\title{
Migrations of Cultures in British New Guinea.
}

\section{The Huxley Memorial Lecture for igro.}

THE Huxley memorial lecture of the Royal Anthropological Institute was delivered by Dr. A. C. Haddon at the rooms of the Royal Society on November 23.

In opening his address Dr. Haddon suggested that the immediate cause of the interest taken by Huxley in anthropology may have been the memorable voyage which he made more than seventy years ago in the Rattlesnake when he was sent out to survey the marine zoology of the Torres Straits and various parts of the coast of New Guinea. He himself had been first attracted to anthropology when in 1888 he visited the Torres Straits, also with the object of studying marine zoology. It was therefore, in his opinion, not inappropriate that it had fallen to his lot to pay homage to the memory of a master of scientific method and of clear exposition, and that he should select the area of their respective first experiences in travel for the subject of his discourse.

On the coast of British New Guinea is found a series of cultures, some of which are evidently related, others as obviously unrelated. Their affinity suggests a common origin, but any idea of indigenous development or of cultural migration from Australia may at once be dismissed.

The cultural problems of the south-eastern peninsula and of the outlying islands of New Guinea are, in the main, quite distinct from those to the west, and the differences between the two groups of cultures indicate clearly that there cannot have been any extensive cultural movements from the PapuoMelanesians of the east to the western Papuans. We are thus driven, on general grounds, to the supposition that the cultures of the southern coast of British New Guinea came down more or less from the north.

The Tugeri, who live just beyond the Netherlands border, are cannibals and inveterate head-hunters who chew kava, vati. The inhabitants of several villages assemble at initiation ceremonies, at which bullroarers are swung, but the bullroarer is not known elsewhere in Netherlands New Guinea. There are many dances at which masks are worn and animals represented. The bullroarer is anthropomorphised as Sosom, a mythical monster of the bush, who at the annual festival at the beginning of the south-east monsoon devours the novices, but brings them back to life. There is such a striking resemblance between this complex and that of various tribes in the area from Astrolabe Bay to Huon Gulf that a relationship cannot be denied.

The use of kava has such ethnological interest that it is worth while noting its distribution in New Guinea. Several of the bush tribes west of the Fly estuary chew kava. Effigies of crocodiles are presented with kava by the Masingara, and a legend suggests a former monster who ate novices at the initiation ceremony. Kava plays an important part in the several ceremonies of the Kiwai neoples, and onlv those who have passed through all the stages of initiation may drink it. The Gogolara, who live between the Fly estuary and the Bamu, have an initiation ceremony in which a boy is supposed to be eaten by a crocodile, and kava is drunk. The tribes to the north of Huon Gulf hold a neriodir circumcision ceremonv at which, to the humming of bullroarers, the initiates are dragged into a hut constructed like a monster, which thus symbolically swallows them. An important part of the intiation ceremonies consists in teaching the novices how to play the sacred flutes.

No. 2667 , VOL. IO6]
To return to the south coast. The Kerewa folk live in Goaribari Island and its neighbourhood. They have carved shrines to which sliulls of people who have been eaten are attached. Further east are the Namau group. Here are enormous ceremonial houses with numerous shrines, associated with a manes cult, in front of which are heaps of animal, and formerly of human, skulls. In the dim recess of the building are basketwork monsters. The Elema or Gulf culture, further east, is essentially similar, except that the monsters are lacking and the people are not cannibals.

The Great Sepik River possesses several cultures along its course, one of which is characterised by so many general similarities with the cultures of the south coast that there must have been some connection between them; for example, there are numerous plaitwork masks which find an exact counterpart in the Middle Fly, on the Bamu, and in the Kerewa country. The great difficulty alike in the supposed spread of kava-drinking from the Huon GulfAstrolabe Bay area to the mouth of the Fly and beyond, and in the extension of the Sepik culture to the south coast, is the great mountain chain of New Guinea. It would be easier to suppose that these cultures, which, so far as is known at present, are discontinuous, were carried to their respective areas by seafaring people, but no traces of similar cultures are found in the intervening coastal areas; furthermore, the western canoes (except in the Torres Straits area) are a river type, and can be matched from the Sepik. An interesting problem is that of the woven rattan cuirasses; these occur on the north coast at the Netherlands boundary and some way to the east of it, also some distance inland south of this area, and again on the Palmer River and Upper Fly, and, finally, a feebler type is found in the mountains up the Utakwa River in Netherlands New Guinea. It is inconceivable that a mioration could have carried this armour all round New Guinea and right up the Flv without leaving traces en route. The most rational view is that it has spread down from the north coast, in which case it would have crossed the mountain chain, as the Sepik cultures are assumed to have done.

The south-eastern peninsula of New Guinea is characterised by the absence of the features of the western cultures and the presence of a big feast, with which in the region round Milne Bav is associated the cult of the mango-tree. In the Mamba and Kumusi river-systems initiation ceremonies are again met with, the bullroarer is employed, and a pair of sacred flutes played. The use of the sacred flutes links up with the initiation ceremonies of the peoples to the north of Huon Gulf, and their use extends all along the coastal peoples well into Netherlands territorv, as well as up the Sepik. It seems as if the use of the flutes tended to supplant that of the bullroaror. The distribution of the flutes further coincides fairly closely with the emplovment of slit gongs. Both these instruments appear to belong to a relatively recent cultural movement from northern Melanesia.

From this it will be evident that the ethnological history of New Guinea is extremely complex; movements have taken place within the island, and cul tural influences have come in from without. The south-eastern peninsula has been the scene of twn different migrations, resulting in the Motu and Massim cultures, and probably a third one influenced the Trobriands. These were perfectly distinct from 
the probable migrations from northern Melanesia which have modified the nortnern coastal cultures. These have come on the top of Papuan cultures, the more striking features of which have probably been due to earlier cultural drifts from Indonesia. At present it is only possible to state some of the problems and to hazard conjectures as to their solu- tion. Very much work remains to be done before the history of this fascinating island can be unravelled.

At the conclusion of the address the Huxley memorial medal was presented to the lecturer by Sir Everard im Thurn, the president of the Royal Anthropological Institute.

\section{International Weather Telegraphy.}

$\mathrm{T}^{\mathrm{n}}$ HE International Commission for Weather Telegraphy, appointed at the general Meteorological Conference at Paris in October, 1919, met at the Air Ministry during the week November 22-27. The delegates were welcomed at the first meeting on Monday, November 22, by Major-Gen. Sir F. H. Sykes, Controller-General of Civil Aviation, who emphasised the special need for international agreement in meteorology because nations were more interdependent in respect of that science than of any other.

During the meeting the Commission came to an agreement upon the codes for the transmission of surface observations and upper-air observations in land messages and for a new figure code for the transmission of reports from ships at sea.

It also agreed upon a time-table for the issue by radio-telegraphy of data messages for the preparation of synoptic charts and upon the distribution of stations in Europe for the issue from the Eiffel Tower of collective data messages for the whole European réseau.

The principal changes in the new code are:

(a) The number of figures for reporting barometric tendency is reduced from two to one, and the unit for barometric tendency is standardised as the halfmillibar per three hours, or, for countries using the millimetre scale, the half-millimetre per three hours.

(b) A two-figure code for reporting the weather takes the place of the old single-figure code, and permits the intensity and character of the precipitation to be reported.

(c) Provision is made for reporting visibility up to $30 \mathrm{~km}$. according to a graduated scale.

(d) One figure is allotted to reports of humidity which will be given to the nearest ro per cent.

Prior to I9II the code for international messages provided for reports of the temperature of the wet bulb as well as of that of the dry bulb. The temperature of the wet bulb was omitted after the introduction of barometric tendency, and thereafter no information about humidity was included in the messages. The new conditions, which permit of the international exchange of the full report for I p.m. and 6 p.m., and for the inclusion of humidity in the upper air for reports of surface humidity, should prove of considerable value.

(e) One five-figure group is allotted to reports of the form, amount, and height above ground of the clouds. It may be noted that the height of the clouds above ground and the visibility are at present the two elements of the greatest importance to aviation.

(f) Provision is made for reporting twice a day the hour of commencement of rainfall. This has been proved to be of great value by actual trial in Scandinavia, and it is anticipated that it will ultimately be one of the most important data in the preparation of forecasts for agriculture.

(g) A special group of five figures is allotted to a selection of stations in each country for the purpose of reporting as exactly as possible the direction and relative speed obtained by neohoscopic observations of clouds.

(h) Three special groups are allotted to selected No. 2667 , VOL. IO6] stations in each country for reporting the direction and speed of the upper wind as determined by observations with pilot-balloons, shell-bursts, kiteballoons, and other methods.

(i) Ten groups as a maximum have been allotted to one, two, or three stations in each country where facilities are available for obtaining the temperature and humidity of the upper air to great altitudes by means of aeroplanes or kite-balloons.

In connection with the observations of the upper air, the Commission was interested to learn from Prof. de Quervain of the proposal to establish a station in Switzerland at an altitude of 3500 metres, from which barometric observations would be of the highest value in the construction of charts for that level.

The code adopted for the reports by wireless telegraphy from ships at sea provides for the same information as that which is given in the messages un land with the omission of barometric tendency, relative humidity, and the height of clouds. A new feature is the introduction of the method of checking the reports already used in the Meteorological Service of India. The necessity for some system of this kind was emphasised at the Meteorological Conference at Innsbruck in 1905 during a discussion on the possibility of obtaining wireless messages from the Atlantic. The new code provides a simple and practical method for discovering any error which exists and for correcting it.

The Commission learned with much interest that meteorological observations were being made this winter on behalf of the Norwegian Institute in the Island of Jan Mayen, which is situated about 600 miles north-east of Iceland; and that there was a prospect in the not distant future of obtaining meteorological observations from Greenland by radiotelegraphy.

The hard work of the business meetings of the Commission was relieved by a number of social gatherings. On November 22 Sir Napier and Lady Shaw gave a reception to the delegates at ro Moreton Gardens, S.W. On the afternoon of November 24 a visit was paid by the delegates to Croydon Aerodrome, and an opportunity afforded them of seeing the meteorological and wireless arrangements necessary at the terminus of air routes. On November 25 the delegates were entertained to luncheon at the Carlton Hotel by his Majesty's Government, when the Marquess of Londonderry, Under-Secretary of State for Air, referred in a characteristic speech to the achievements of the delegates, some of whom had come from countries so widely separated, both by distance and by climate, as Java and Iceland. On the evening of November 26 the Maharaj Rana of Jhalawar gave a dinner in honour of the delegates; they were one and all delighted with the informal hospitality of his Highness, who had assisted at the last meeting of the Commission in 1912 and had maintained his interest in meteorology, especially British meteorology, which had made notable advances under the direction of Sir Napier Shaw, the president of the International Meteorological Committee. 